\title{
Exploring the tumors of multiple endocrine neoplasia type 1 in mouse models for basic and preclinical studies
}

Most patients (70-90\%) with the multiple endocrine neoplasia type 1 (MEN1) syndrome possess germline heterozygous mutations in MEN1 that predisposes to tumors of multiple endocrine and nonendocrine tissues. Some endocrine tumors of the kinds seen in MEN1 that occur sporadically in the general population also possess somatic mutations in MEN1. Interestingly, the endocrine tumors of MEN1 are recapitulated in mouse models of Men1 loss that serve as a valuable resource to understand the pathophysiology and molecular basis of tumorigenesis. Exploring these endocrine tumors in mouse models using in vivo, ex vivo and in vitro methods can help to follow the process of tumorigenesis, and can be useful for preclinical testing of therapeutics and understanding their mechanisms of action.

Keywords: cell cycle $\bullet$ epigenetic $\bullet$ MEN1 $\bullet$ menin $\bullet$ mouse models $\bullet$ tumor suppressor - tumorigenesis

Multiple endocrine neoplasia type 1 (MEN1) is an autosomal-dominant tumor syndrome manifesting as endocrine tumors in adults (age 40-50 years) in the parathyroid (90\%), pancreas/duodenum (50\%) and pituitary $(40 \%)[1,2]$. MEN1 cases have at least two of the three main associated endocrine tumors, and familial MEN1 cases have at least one first-degree relative with tumor in at least one of these three tissues [3]. Other endocrine and nonendocrine tumors of MEN1 are: adrenal cortical tumors, foregut carcinoids, meningioma, uterine leiomyoma and skin lesions - angiofibromas, collagenomas and lipomas $[4,5]$. Most endocrine tumors of MEN1 are benign but they cause symptoms by producing and secreting excess hormones or by local mass effects, while some MEN1 tumors have the potential to be malignant (Table 1).

Most index cases with familial MEN1 (70-90\%) have a heterozygous germline mutation in the MEN1 gene (first hit) located on chromosome 11q13, and tumors show loss of the remaining normal copy of MEN1 (second hit); thus MEN1 functions as a tumor suppressor $[6,7]$. The frequency of
MEN1 germline mutation is much lower in MEN1 index cases without a family history of MEN1 (1-10\%) [2]. MEN1 is rare but the sporadic counterpart tumors of MEN1 occur more commonly. Somatic MEN1 mutation is observed in $30-40 \%$ of common tumors of the parathyroids or pancreas/duodenum, but in only $3 \%$ of common pituitary tumors [8-12]. More than 500 unique mutations have been identified in MEN1 (mostly in the coding region and splice junctions) with no apparent genotype/phenotype correlations [13]. Few MEN1 cases ( $<2 \%)$ show rare germline mutations in the $C D K N 1 B / p 27$ gene (MEN4 syndrome) that encodes p27 one of the cyclin-dependent kinase inhibitors (CDKI), or other CDKI family members [14,15]. However, the clinical phenotype distinct from typical MEN1 with complete or incomplete disease features is not clearly defined. Somatic CDKN1B/p27 mutations have been identified in $8-10 \%$ of sporadic small intestine neuroendocrine tumors [16]. Identification of other mechanisms of inactivating $M E N 1$, and identification of mutations in other genes is necessary to elucidate

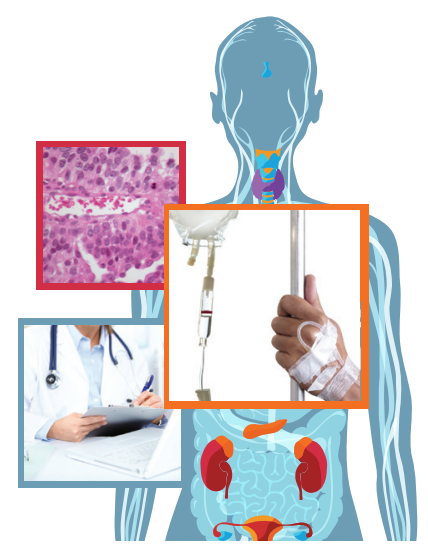

International Journal of Endocrine Oncology

Sunita K Agarwal

National Institutes of Health, NIDDK, Metabolic Diseases Branch, Bldg 10, Room 8C-101, Bethesda, MD 20892, USA Tel.: +1 3014027834

Fax: +1 3014020374

sunitaa@mail.nih.gov 
the genetic cause of tumors in MEN1 cases and sporadic tumors that lack $M E N 1$ mutations.

The MEN1 gene encodes a 610 amino acid protein named menin (NCBI Reference Sequence: NM_130799.2, human menin isoform-2) [17]. Menin is a ubiquitously expressed $67 \mathrm{kDa}$ predominantly nuclear protein reported to undergo phosphorylation at six different amino acid residues - Ser394, Thr397, Thr399, Ser487, Ser543 and Ser583 [17,18]. Approximately 40 different proteins associated with diverse functions have been shown to partner with menin in the nucleus or cytoplasm [17]. Several lines of evidence show that menin is associated with the regulation of transcriptional activation or repression from its interaction with transcription factors or chromatin-modifying protein complexes [17]. However, the importance of phosphorylation and interactions of menin with various proteins in the context of endocrine tumorigenesis remains to be determined.

Mouse models can serve as effective experimental surrogates of autosomal dominant human genetic disorders, such as MEN1. Also, mouse models with tumors of MEN1 from manipulation of other relevant genes can provide insights about the genetic and molecular interactions that lead to tumor formation. This review surveys the mouse models that present with the endocrine tumors of MEN1 and describes the use of these mouse models to investigate the molecular and genetic interactions associated with endocrine tumorigenesis and the potential of preclinical studies in these mouse models in the investigation of therapeutics. This review contains information gathered from the existing literature, and does not contain any unpublished original results from the author.

\section{Tumor spectrum in the conventional mouse models of MEN1 versus human MEN1 syndrome}

Four different conventional germline Menl knockout mouse models have been generated that target and delete different Men 1 exons (labeled A, B, C and D in Table 1) [19-22]. The germline homozygous knockout mice are small in size and die during mid-gestation at embryonic days E10.5-E14.5 with craniofacial, neural tube, heart and liver developmental defects [19-25]. Similar to the human MEN1 syndrome, the germline heterozygous mice spontaneously lose the normal copy of Menl in the MEN1-associated endocrine tissues and show an endocrine tumor spectrum that resembles the human syndrome. After 12 months, the mice develop the main endocrine tumors of MEN1 in the parathyroids, pancreas, anterior pituitary and adrenals. Considering the differences in lifespan, the age at onset of tumors (12-18 months) in the mouse models with spontaneous second hit closely coincides with the age at onset of human MEN1 [26].

Similar to humans with MEN1, mice with MEN1 show anterior pituitary tumors predominantly in females [8,27]. In human MEN1, gastrinomas occur more frequently (40\%) compared with insulinomas $(10 \%)$ and nonfunctioning tumors (10\%). However, in mouse models the pancreas/duodenum tumors are mainly insulinomas (28-88\%) with significantly decreased blood glucose levels, and gastrinoma is observed in only one model (15\%) (Table 1). The foregut carcinoids and nonendocrine tumors seen in human MEN1 cases are not observed in the mouse models except for the occurrence of a lipoma in one mouse model [22]. Some tumor types seen in mouse MEN1 do not occur in human MEN1 patients, for example, bilateral pheochromocytoma and gonadal tumors (in both male and female mice).

These mouse models confirm that germline heterozygosity of MEN1 predisposes to tumorigenesis in multiple endocrine organs raising the possibility that these tissues could have similar mechanisms that control their growth and development. Exploring the tumors of MEN1 could provide insights about these endocrine cell-specific growth-control mechanisms. The conventional mouse models could serve as experimental surrogates of the human MEN1 condition to explore the in vivo progression of the MEN1 syndrome. Studies using genomic and proteomic approaches with tumors from the mouse models are warranted to explore tumor pathogenesis and pathways relevant to tumor formation and to identify other possible genetic/epigenetic hits after Men 1 loss that play a role in tumorigenesis. With advances in techniques that use very small amounts of RNA, DNA, protein or chromatin, such studies could be done with tumors and corresponding normal tissues from the mouse models of MEN1 tumors. For example, a recent study performed whole-genome sequencing of a tumor from a mouse model of acute myeloid leukemia and identified leukemia progression mutations relevant for human leukemia [28]. These mutations were previously only observed in single human cases. The driver nature of these mutations is now validated due to their occurrence in the mouse cancer genome.

\section{Tumors of MEN1 in endocrine-targeted homozygous Men1 knockout mouse models}

Mouse models with conditional homozygous knockouts of Men1 in MEN1-associated endocrine target tissues have been generated using standard Cre-Lox strategies, and these mice are viable. Mice carrying floxed MenI alleles (MenIfff) have been crossbred with mice expressing the Cre-recombinase from different tissuespecific promoters to selectively inactivate both copies 
Table 1. Tumors associated with the MEN1 syndrome in man and mouse.

Tumors

Human (at age

Mouse (Men1+-- at age 12-18 months), \%

40 years), \%

$\begin{array}{llll}A^{\dagger} & B^{\ddagger} & C^{\S}\end{array}$

Endocrine (hormone-secreting or NF)

Parathyroid

90

24

$47 \quad 9$

85

Pancreas (entero-pancreatic neuroendocrine):

- Gastrinoma\#

40

- Insulinoma

10

15

- NF, PPoma\#

20

- Glucagonoma\#, VIPoma\#,

- Somatostatinoma\#, etc.

Anterior pituitary:

- Prolactinoma

- $\mathrm{GH}+$ prolactin-secreting

12

10

- $\mathrm{GH}$-secreting

5

28-83 88

82

60

- NF

5

- ACTH-secreting

5

Adrenal:

- Cortex NF

2

3

- Medulla

25

20-43

35

10

10

- Pheochromocytoma

1

Foregut carcinoid:

- Gastric ECLoma NF

$-$

7

32

ๆ

- Thymic carcinoid" NF

10

- Bronchial carcinoid" NF

4

Nonendocrine

Facial angiofibroma $\quad 85$

Truncal collagenoma $\quad 70$

Lipoma 30

Meningioma 5

Barrett's esophagus 5

Leiomyoma:

- Uterus (in female) 30

- Esophagus 5

Ependymoma 1

Lung (adenocarcinoma) -

Testis, Leydig cell (in male)

22

Ovary, sex-cord stromal (in female)

- 22

22

$\begin{array}{ll}- & 31\end{array}$

$\begin{array}{llll}22 & 88 & 47 & 60 \\ 31 & 8 & & 40\end{array}$

${ }^{+}$Crabtree et al. 2001 [19], Balasubramanian and Scacheri 2009 [26], \% from TSM exon3-8, \% after hyphen from dNexon3-8. "Bertolino et al. 2003 [20], exon 3.

'Loffler et al. 2007 [21], exon 2.

"Harding et al. 2009 [22], exon 1-2.

"Tumor type with malignant potential for $25 \%$ or more human cases. Mouse models and exons deleted.

ACTH: Adrenocorticotropic hormone; ECLoma: Tumor of enterochromaffin-like cells; GH: Growth hormone; NF: Nonfunctioning:

PPoma: Tumor secreting pancreatic polypeptide; VIPoma: Tumor-secreting vasoactive intestinal polypeptide.

Adapted with permission from [8]. 
of endogenous Men1 in the target tissues: parathyroid hormone promoter (PTH-Cre, for parathyroid cells), Villin promoter and Lgr5 promoter (Villin-Cre and Lgr5-CreERT2, for antral and intestinal epithelium, respectively), rat insulin promoter (Rip-Cre, for islet $\beta$-cells), glucagon promoter (GLU-Cre, for islet $\alpha$-cells) and Pdx1 promoter (Pdx1-Cre for whole pancreas, exocrine and endocrine). Unlike the conventional germline Men 1 heterozygous mice, conditional mice are not dependent on the spontaneous tissue-specific second hit to the Men 1 gene; therefore, tumor formation in the conditional mice occurs at an earlier age.

Parathyroid hyperplasia and hypercalcemia are observed in the parathyroid-specific Menl knockout mouse model after 7-9 months [29]. The gastrointestinal epithelium-specific Men1 knockout mice do not develop gastrinoma, but they show hypergastrinemia from antral G-cell hyperplasia and a hyperproliferative epithelium [30]. Insulinomas (adenoma or carcinoma) develop in most islets at $6-8$ months in the pancreatic islet $\beta$-cell-specific Menl knockout mouse models, with islet hyperplasia as early as 4 weeks [31-33]. Although a pituitary-specific knockout of Men1 has not been published, older (>12 months) Rip-Cre;

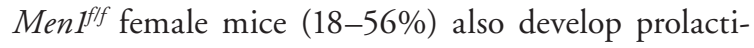
nomas due to leaky Cre expression from the Rip-Crepromoter in the pituitary cells [31-33]. The occurrence of the tumors specifically in the lactoprophs shows that specific inactivation of Menl in this cell type can cause tumors. Surprisingly, two different mouse models of pancreatic islet $\alpha$-cell-specific Men 1 loss show mostly insulinomas rather than the expected glucagonoma $[34,35]$. The unexpected phenotype has been attributed to transdifferentiation of $\alpha$-cells into $\beta$-cells or from potential paracrine signals from the Men1 knockout $\alpha$-cells that induce $\beta$-cell proliferation. Another surprising finding is in the whole pancreas knockout Men1 mouse model (Pdx-Cre; Men $1^{f f f}$ ), which develops a single tumor only in the endocrine pancreatic $\beta$-cells (insulinomas), rather than tumors of all pancreatic cells or the multiple insulinomas in the Rip-Cre; Men $f^{f f}$ mice [36]. Therefore, mice knockout for Men 1 in the whole pancreas, in the $\alpha$-cells or $\beta$-cells, all develop only $\beta$-cells tumors; underscoring the importance of menin in $\beta$-cell proliferation.

Although menin is haplosufficient for the development of all tissues, menin haploinsufficiency is observed in Men1 knockout mouse islets (conventional and conditional knockout mice) leading to increased $\beta$-cell proliferation and hyperplasia prior to tumor formation [19-22,31-33]. This precursor stage of polyclonal hyperplasia is not observed in humans. Although loss of menin expression occurs early in embryogenesis in all the conditional Men 1 knockout mice, delayed tumor formation implicates other hits for tumor formation. The lack of chromosomal or microsatellite instability in the insulinoma of Rip-Cre; Men $1^{f f f}$ mice has suggested that mutations might occur at the nucleotide level or epigenetic mechanisms might be affected [37]. These conditional Men1 knockout mice with accelerated tumorigenesis can be useful models to test drug treatments in younger animals and in specific endocrine tumors.

\section{Tumors of MEN1 in mouse models of cell cycle control genes with or without Men1}

Conventional mouse models engineered to express or knockout a single or combination of some cell cycle control genes develop the endocrine tumor types observed in MEN1. These include $R b, C c d n 1 / c y c l i n D 1$, a cyclindependent kinase (Cdk4) and a few CDKIs, $p 18, p 21$ and $p 27$. Although mouse models with germline $R b$ loss $\left(R b^{+-}\right)$mainly show intermediate lobe pituitary tumors, $R b^{+/}$mice in the $\mathrm{C} 57$ background show high penetrance for anterior pituitary tumors [38]. Mouse strain backgrounds did not have any effect on the development of prolactinomas in the MEN1 mouse models: mouse background C57/129 [21,22], C57/129SvTacFBR (TSM) or C57BL/6 (dN3-8) [19,26] or 129/Ola,129/Sv (Table 1) [20]. Mice with simultaneous germline loss of p27 or $p 21$ with loss of $p 18$ develop an endocrine tumor spectrum that overlaps with both MEN1 and MEN2: hyperplasia and/or tumors of the parathyroid, endocrine pancreas, pituitary, adrenals, duodenum, stomach, testes and thyroid $C$ cells [39]. Hyperplasia in the islet $\beta$-cells is observed in conventional mice expressing a constitutively active form of CDK4 (CDK4-R24C) and in mice with $\beta$-cell-specific cyclinD1 overexpression $[40,41]$.

$M e n 1^{+/}$mice with combined loss of $R b$, or $p 27$, or $C d k 2$ do not show any difference in the phenotype and tumor spectrum compared with $\mathrm{Men1}^{+{ }^{+-}}$mice [42-45]. While $C d k 4^{-1-}$ mice show hypoplasia of the pituitary and pancreatic islets, $M e n 1^{+/}$mice with combined loss of $C d k 4$ do not develop any tumors and possess hypoplastic islets and pituitaries without loss of heterozygosity for Men1 [45]. Men1 ${ }^{+-}$mice with combined loss of p18 show tumors at an early age (3-12 months) with an increased penetrance for anterior pituitary tumors, insulinomas, parathyroid adenoma, adrenal cortical tumors and lung tumors [42]. However, these tumors do not lose the second copy of Menl, suggesting that p18 participates together with menin as a tumor suppressor in endocrine tissues. It is possible that the function of p27 is already maximally compromised in the Men1 ${ }^{+/-}$mice and the additional loss of p27 is refractory to any effect on tumor formation; therefore, p27 overexpression in endocrine tumors of mouse models of Men1 loss might be useful to test the hypothesis that p27 could block tumorigenesis in Men1 ${ }^{+/}$mice [26]. 
Reduced expression of CDKIs p15, p18, p21 and p27 has been observed in pancreatic islet tumors from $M e n 1^{+/}$mice [46]. The MENX syndrome in rat and the MEN4 syndrome in man are caused by germline mutations in $p 27$ [14]. Also, possible rare germline mutations in 3 other CDKI genes $(p 15, p 18$, and $p 21)$ are reported in MEN1 and MEN1-like disease [15]. These observations together with the mouse models described above highlight the importance of cell cycle regulators in endocrine tumorigenesis and warrant further studies to explore the therapeutic potential of CDKIs.

\section{Tumors of MEN1 in mouse models with combined knockout of Men1 with p53 or $R b p 2$}

To understand the contribution from interplay of different genes with Men1 and their impact on MEN1 tumors, two other mouse models have been generated with combined loss of Men1 with $p 53$ or $R b p 2$. Mice with knockout of the tumor suppressor $p 53$ $\left(\operatorname{Trp} 53^{+/}\right)$in an $\mathrm{Men} 1^{+/}$background show independent and nonsynergistic effects on tumorigenesis, possibly indicating that disruption of the p 53 pathway is not relevant for the endocrine tumors of MEN1 [43]. Menin partners with two similar multiprotein MLLcomplexes, containing either MLL1 or MLL2 with an enzymatic activity (histone methyltransferase, HMTase) that catalyzes the trimethylation of histone $\mathrm{H} 3$ at lysine 4 [47,48]. This specific histone modification (H3K4me3) is associated with the activation of gene transcription. RBP2 (also known as KDM5B or JARID1B) is a histone demethylase that can remove the trimethylation at $\mathrm{H} 3 \mathrm{~K} 4 \mathrm{me} 3$ [49]. Mice inactivated for Men 1 in $\beta$-cells are defective for $\mathrm{H} 3 \mathrm{~K} 4 \mathrm{me} 3$ on specific genes, not only from loss of the menin-MLL complexes but also owing to increased activity of the demethylase Rbp2, which can act at $\mathrm{H} 3 \mathrm{~K} 4 \mathrm{me}$. In such conditional $\beta$-cell-specific Men 1 knockout mice, $\beta$-cell-specific loss of $R b p 2$ rescued tumorigenesis and enhanced median survival age from 45 weeks (Men1 knockout in $\beta$-cells) to 69 weeks (combined knockout of Men1 and Rbp2 in $\beta$-cells) [50]. Therefore, inhibition of the histone demethylase activity of Rbp2 could be potentially therapeutic in insulinomas.

\section{Exploring the tumors of MEN1 in mouse models for preclinical applications}

Genetically engineered mouse models of disease can be useful for preclinical applications, such as for screening the potential safety, activity and efficacy of drug compounds, testing transgene delivery methods and for ex vivo tumor transplantation studies. Below are summarized five different studies published to date that have used different mouse models of MEN1 tumors.
The proliferation rates of the endocrine tumors of MEN1 have been investigated by long-term labeling with the thymidine analog 5-bromo-2-deoxyuridine (BrdU). The proliferation and kinetics of tumors of the pancreas, pituitary and adrenals was investigated in 18-21-month-old conventional Men1 knockout mice [22,51]. Mice fed with $\mathrm{BrdU}$ in the drinking water, to allow continuous labeling of proliferating cells for 1-12 weeks, were assessed for tumor cell proliferation rate and apoptosis. The analysis using a mathematical model of neuroendocrine tumor cell proliferation predicted that the lifespan of mice was sufficient for studying tumors of the pancreatic $\beta$-cells, and two different pituitary cell types (lactotrophs and somatotrophs) but not for non- $\beta$-cell pancreatic neuroendocrine tumors (PNETs). This technique and analysis could be useful to assess the efficacy of novel treatments in mouse models to reduce tumor cell proliferation, such as monoclonal antibodies, gene replacement and other genetic/epigenetic modifying agents.

A preclinical evaluation of $M E N 1$ gene therapy has been conducted in the pituitary tumors of $M e n 1^{+/}$mice by transauricular intratumoral injection with Men1. rAd5 (a recombinant nonreplicating adenoviral serotype 5 vector with the murine Men 1 cDNA under the control of a cytomegalovirus promoter) [22,52]. Tumor growth characteristics in $55 \mathrm{Menl}^{+/-}$female mice treated with Men1.rAd5 (and control mice) were studied by feeding BrdU in the drinking water for 4 weeks followed by MRI and immunohistochemical analysis. The Men1.rAd5-injected tumors showed significantly reduced daily proliferation rates. This study demonstrated that MEN1 gene replacement therapy by direct injection in the tumor could effectively express ectopic menin to reduce tumor cell proliferation.

Germline $\mathrm{Men1}^{+/-}$mice [21] have been used to study the efficacy of an antiangiogenesis treatment with the anti-VEGF-A monoclonal antibody mAb G6-31 to inhibit the growth of pituitary tumors and insulinomas [53]. Anti-VEGF-A mAb G6-31 (or control antibody $\mathrm{IgG}$ ) was administered to 125 female $\mathrm{MenI}^{+/-}$ mice at age 11-13 months for 67 days or until mice were found moribund. Significant decrease in the mean pituitary tumor volume and prolactin levels was observed 39 days after treatment in the mAb G6-3 treated animals. A similar efficacy was observed against insulinomas. This study also established a transplantable model of MEN1 mouse pituitary tumors in $\mathrm{BALB} / \mathrm{c}$ nude mice, which produced high levels of prolactin and responded well to anti-VEGF-A therapy. The availability of transplantable ex vivo models of MEN1 endocrine tumors can facilitate and hasten the investigation of such tumors that require many months to establish in vivo in the mouse models. 
PNETs in human MEN1 and in the Pdx1-Cre; Men $1^{f f f}$ mouse model show increased vasculature and upregulation of VEGF expression, a known contributor to angiogenesis [36]. Using the insulinoma in the Pdx1-Cre; Men $f^{f f}$ mice as a model, inhibition of VEGF signaling was investigated with sunitinib, a known small-molecule tyrosine kinase inhibitor of all VEGF receptors [36]. Four to eight sex-matched and weight-matched Men $f^{f f}$ and Pdx1-Cre; Men ${ }^{f f f}$ mice at age 3 months were treated with vehicle or sunitinib via daily oral gavage for 3 months. Significantly reduced cell proliferation and reduced islet vascularity was observed in Pdx1-Cre; Men $f^{f f}$ animals treated with sunitinib. This study demonstrated that VEGF signaling was a critical pathway in the PNET that developed in this mouse model of MEN1.

Using a novel single islet and tumor perfusion technique, wild-type or germline $\mathrm{Men}^{\mathrm{I}^{+-}}$young (4-6 months, $\mathrm{n}=7$ per genotype) and older mice ( $>12$ months, $\mathrm{n}=7$ per genotype) have been used to study molecular, morphological and physiological vascular alterations in the endocrine pancreas and in PNETs [21,54]. Differential regulation was observed for the vascular contractile responses to vasoactive agents (D-glucose and L-NAME) in tumor and normal isletsupplying capillaries. The vascular differences were accompanied by differential expression of multiple angiogenic factors (VEGF-A/VEGFR2/PIGF and FGF2/FGFR1 pathways) with some already expressed in the islets of normal looking $\mathrm{MenI}^{+/}$islet tissue. These data implicate a possible haploinsufficient state of the $\mathrm{MenI}^{+-}$- islet that precedes tumor formation.

Unlike the other mouse models of Men1 loss (conventional or Rip-Cre; Men $1^{f f f}$ ), the Pdx1-Cre; Men fff $^{f f}$ mouse model shows only a single insulinoma in the pancreas [36]. All somatostatin receptor types (SSTRs 1-5) are expressed in the PNET tissue of the Pdx1Cre; Men $1^{f f f}$ mouse model [55]. Therefore, the efficacy of a somatostatin analog, Pasireotide (SOM230), was assessed [55]. Eight 12-month-old Pdx1-Cre; Menfff mice with insulinoma were treated with monthly subcutaneous injections of SOM230 or PBS. Significantly decreased serum insulin levels and a significant increase in serum glucose in the treatment group were observed on day 7. Also, a reduction in tumor size and increased apoptosis was detected in the treatment group. This study demonstrated the antisecretory, antiproliferative and proapoptotic activity of SOM230 in the Pdx1-Cre; Men ${ }^{f f f}$ MEN1 model of insulinoma.

\section{Conclusion \& future perspective}

Studies of MEN1 tumors in mouse models have confirmed that germline heterozygosity of MEN1 can predispose to tumorigenesis in multiple endocrine organs and have been useful to explore tumor progression in specific endocrine tissues, and menin's functional interaction with cell cycle regulators and with histone methylating and demethylating proteins. At the same time, several mechanistic and biological aspects remain to be determined, such as the reason for the second hit to the Men 1 locus in only certain selected endocrine tissues, the endocrine cell-type specificity of tumorigenesis in the pancreas and the reason for the delay in tumor formation even in the conditional mouse models. More than 30 different endocrine and nonendocrine tissues are affected in the human MEN1 syndrome (Table 1). It is not known why the nonendocrine tumors are not

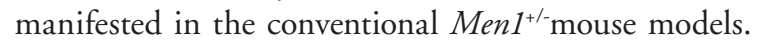
Although mouse background has been shown to affect the embryonic lifespan of the Men1-null mouse [25], similar data about the effect of mouse genetic background have not been formally gathered for the endocrine tumors of MEN1. The above aspects can be determined by developing new experimental mouse models.

Another aspect for future study in the mouse models is to test the treatment of endocrine tumors with drugs that mimic p18 to inhibit CDKs, or drugs that target epigenetic modifications. Menin's participation in histone-modifying protein complexes and the reduced islet tumor burden and increased lifespan of the compound conditional Men1/Rbp2 knockout mouse model shows that epigenetic drug targets could be relevant for the treatment of MEN1 tumors.

The hyperplastic islets in the MEN1 mouse models retain their differentiated $\beta$-cell characteristic to produce and secrete hormones. Therefore, understanding the molecular basis of their proliferation capacity can help to develop methods for $\beta$-cell expansion/replacement in conditions of $\beta$-cell loss, such as in diabetes.

Future studies in the mouse models of MEN1 tumors will help to uncover molecular events that govern disease progression in the early stages that precede tumor formation. Such studies are not possible to implement in human patients. Elucidating the pathways perturbed during tumorigenesis in the tumors of MEN1 in mouse models will help to identify targets downstream of Men1 loss that also could reveal genes causative for sporadic tumors that lack $M E N 1$ mutation. Ultimately it is very important to understand the manifestation of $M e n 1 /$ menin deficiency in murine models at the molecular level and how that relates to human patients.

\section{Financial \& competing interests disclosure}

This work was supported by the Intramural Research Program of the NIH, National Institute of Diabetes and Digestive and Kidney Diseases (Project number: 1ZIADK075035-03). The author has no other relevant affiliations or financial involvement with any organization or entity with a financial interest 
in or financial conflict with the subject matter or materials discussed in the manuscript apart from those disclosed.
No writing assistance was utilized in the production of this manuscript.

\section{Executive Summary}

- Mouse models with germline heterozygous loss of Men1 resemble the endocrine tumor phenotype of the human multiple endocrine neoplasia type 1 (MEN1) syndrome.

- Mouse models with germline homozygous loss of Men1 die during embryogenesis, whereas mouse models with homozygous loss of Men1, specifically in the MEN1-associated endocrine tissues, are viable and develop tumors.

- Mouse models of a few specific cell cycle control genes also show endocrine tumors of MEN1.

- Mouse models with combined loss of Men1 and other relevant genes provide insights about the interplay of these genes with Men1 to explore disease-associated pathways.

- Islet tumors from the mouse models of Men1 loss reveal a multistep process of tumorigenesis.

- Tumors of MEN1 in mouse models serve as a valuable resource for preclinical testing of treatment options, such as menin replacement, angiogenesis inhibitors and a somatostatin analog.

\section{References}

Papers of special note have been marked as:

- of interest; $\bullet$ of considerable interest

1 Marx SJ. Molecular genetics of multiple endocrine neoplasia types 1 and 2. Nat. Rev. Cancer 5(5), 367-375 (2005).

2 Thakker RV. Multiple endocrine neoplasia type 1 (MEN1). Best Pract. Res. Clin. Endocrinol. Metab. 24(3), 355-370 (2010).

3 Thakker RV, Newey PJ, Walls GV et al. Clinical practice guidelines for multiple endocrine neoplasia type 1 (MEN1). J. Clin. Endocrinol. Metab. 97(9), 2990-3011 (2012).

-. Very informative paper about the characteristics of multiple endocrine neoplasia type 1 (MEN1) and clinical recommendations.

4 Schussheim DH, Skarulis MC, Agarwal SK et al. Multiple endocrine neoplasia type 1: new clinical and basic findings. Trends Endocrinol. Metab. 12(4), 173-178 (2001).

5 Jensen RT, Berna MJ, Bingham DB, Norton JA. Inherited pancreatic endocrine tumor syndromes: advances in molecular pathogenesis, diagnosis, management, and controversies. Cancer 113(7 Suppl.), 1807-1843 (2008).

6 Chandrasekharappa SC, Guru SC, Manickam P et al. Positional cloning of the gene for multiple endocrine neoplasiatype 1. Science 276(5311), 404-407 (1997).

7 Lemmens I, Van De Ven WJ, Kas Ket al. Identification of the multiple endocrine neoplasia type $1(M E N 1)$ gene. The European Consortium on MEN1. Hum. Mol. Genet. 6(7), 1177-1183 (1997).

8 Agarwal SK, Ozawa A, Mateo CM, Marx SJ. The MEN1 gene and pituitary tumours. Horm. Res. 71(Suppl. 2), 131-138 (2009).

9 Jiao Y, Shi C, Edil BH et al. DAXX/ATRX, MEN1, and $m T O R$ pathway genes are frequently altered in pancreatic neuroendocrine tumors. Science 331(6021), 1199-1203 (2011).

10 Cromer MK, Starker LF, Choi M et al. Identification of somatic mutations in parathyroid tumors using whole-exome sequencing. J. Clin. Endocrinol. Metab. 97(9), E1774-E1781 (2012).
11 Newey PJ, Nesbit MA, Rimmer AJ et al. Whole-exome sequencing studies of nonhereditary (sporadic) parathyroid adenomas. J. Clin. Endocrinol. Metab. 97(10), E1995-E2005 (2012).

12 Newey PJ, Nesbit MA, Rimmer AJ et al. Whole-exome sequencing studies of nonfunctioning pituitary adenomas. J. Clin. Endocrinol. Metab. 98(4), E796-E800 (2013).

13 Lemos MC, Thakker RV. Multiple endocrine neoplasia type 1 (MEN1): analysis of 1336 mutations reported in the first decade following identification of the gene. Hum. Mutat. 29(1), 22-32 (2008).

14 Lee M, Pellegata NS. Multiple endocrine neoplasia type 4. Front. Horm. Res. 41, 63-78 (2013).

15 Agarwal SK, Mateo CM, Marx SJ. Rare germline mutations in cyclin-dependent kinase inhibitor genes in multiple endocrine neoplasia type 1 and related states. J. Clin. Endocrinol. Metab. 94(5), 1826-1834 (2009).

16 Francis JM, Kiezun A, Ramos AH et al. Somatic mutation of $C D K N 1 B$ in small intestine neuroendocrine tumors. Nat. Genet. 45(12), 1483-1486 (2013).

- A recent report with the most number of p27 mutations in any disease.

17 Agarwal SK. Multiple endocrine neoplasia type 1. Front. Horm. Res. 41, 1-15 (2013).

-. Covers clinical, genetic and basic findings about the MEN1 syndrome, MEN1 gene and menin.

18 Francis J, Lin W, Rozenblatt-Rosen O, Meyerson M. The menin tumor suppressor protein is phosphorylated in response to DNA damage. PLoS ONE 6(1), e16119 (2011).

19 Crabtree JS, Scacheri PC, Ward JM et al. A mouse model of multiple endocrine neoplasia, type 1, develops multiple endocrine tumors. Proc. Natl Acad. Sci. USA 98(3), 1118-1123 (2001).

20 Bertolino P, Tong WM, Galendo D, Wang ZQ, Zhang CX. Heterozygous Men1 mutant mice develop a range of endocrine tumors mimicking multiple endocrine neoplasia type 1. Mol. Endocrinol. 17(9), 1880-1892 (2003). 
21 Loffler KA, Biondi CA, Gartside M et al. Broad tumor spectrum in a mouse model of multiple endocrine neoplasia type 1. Int. J. Cancer 120(2), 259-267 (2007).

22 Harding B, Lemos MC, Reed AA et al. Multiple endocrine neoplasia type 1 knockout mice develop parathyroid, pancreatic, pituitary and adrenal tumours with hypercalcaemia, hypophosphataemia and hypercorticosteronaemia. Endocr. Relat. Cancer 16(4), 1313-1327 (2009).

23 Biondi C, Gartside M, Tonks I, Paterson C, Hayward NK, Kay GF. Targeting and conditional inactivation of the murine Men1 locus using the Cre recombinase: loxP system. Genesis 32(2), 150-151 (2002).

24 Bertolino P, Radovanovic I, Casse H, Aguzzi A, Wang ZQ, Zhang CX. Genetic ablation of the tumor suppressor menin causes lethality at mid-gestation with defects in multiple organs. Mech. Dev. 120(5), 549-560 (2003).

25 Lemos MC, Harding B, Reed AA et al. Genetic background influences embryonic lethality and the occurrence of neural tube defects in Men 1 null mice: relevance to genetic modifiers. J. Endocrinol. 203(1), 133-142 (2009).

26 Balasubramanian D, Scacheri PC. Functional studies of menin through genetic manipulation of the Menl homolog in mice. Adv. Exp. Med. Biol. 668, 105-115 (2009).

27 Goudet P, Bonithon-Kopp C, Murat A et al. Gender-related differences in MEN1 lesion occurrence and diagnosis: a cohort study of 734 cases from the Groupe d'etude des Tumeurs Endocrines. Eur. J. Endocrinol. 165(1), 97-105 (2011).

28 Wartman LD, Larson DE, Xiang Z et al. Sequencing a mouse acute promyelocytic leukemia genome reveals genetic events relevant for disease progression. J. Clin. Invest. 121(4), 1445-1455 (2011).

29 Libutti SK, Crabtree JS, Lorang D et al. Parathyroid gland-specific deletion of the mouse Men1 gene results in parathyroid neoplasia and hypercalcemic hyperparathyroidism. Cancer Res. 63(22), 8022-8028 (2003).

30 Veniaminova NA, Hayes MM, Varney JM, Merchant JL. Conditional deletion of menin results in antral G cell hyperplasia and hypergastrinemia. Am. J. Physiol. Gastrointest. Liver Physiol. 303(6), G752-G764 (2012).

31 Crabtree JS, Scacheri PC, Ward JM et al. Of mice and MEN1: insulinomas in a conditional mouse knockout. Mol. Cell Biol. 23(17), 6075-6085 (2003).

32 Bertolino P, Tong WM, Herrera PL, Casse H, Zhang CX, Wang ZQ. Pancreatic beta-cell-specific ablation of the multiple endocrine neoplasia type 1 (MEN1) gene causes full penetrance of insulinoma development in mice. Cancer Res. 63(16), 4836-4841 (2003).

33 Biondi CA, Gartside MG, Waring P et al. Conditional inactivation of the $M E N 1$ gene leads to pancreatic and pituitary tumorigenesis but does not affect normal development of these tissues. Mol. Cell Biol. 24(8), 3125-3131 (2004).

34 Shen HC, Ylaya K, Pechhold K et al. Multiple endocrine neoplasia type 1 deletion in pancreatic alpha-cells leads to development of insulinomas in mice. Endocrinology 151(8), 4024-4030 (2010).

35 Lu J, Herrera PL, Carreira C et al. Alpha cell-specific Men1 ablation triggers the transdifferentiation of glucagon-expressing cells and insulinoma development. Gastroenterology 138(5), 1954-1965 (2010).

36 Shen HC, He M, Powell A et al. Recapitulation of pancreatic neuroendocrine tumors in human multiple endocrine neoplasia type I syndrome via Pdx1-directed inactivation of Men1. Cancer Res. 69(5), 1858-1866 (2009).

37 Scacheri PC, Kennedy AL, Chin K et al. Pancreatic insulinomas in multiple endocrine neoplasia, type I knockout mice can develop in the absence of chromosome instability or microsatellite instability. Cancer Res. 64(19), 7039-7044 (2004).

38 Leung SW, Wloga EH, Castro AF, Nguyen T, Bronson $\mathrm{RT}$, Yamasaki L. A dynamic switch in $\mathrm{Rb}^{+/-}$mediated neuroendocrine tumorigenesis. Oncogene 23(19), 3296-3307 (2004).

39 Franklin DS, Godfrey VL, O’Brien DA, Deng C, Xiong Y. Functional collaboration between different cyclin-dependent kinase inhibitors suppresses tumor growth with distinct tissue specificity. Mol. Cell Biol. 20 (16), 6147-6158 (2000).

40 Rane SG, Cosenza SC, Mettus RV, Reddy EP. Germ line transmission of the $C d k 4(\mathrm{R} 24 \mathrm{C})$ mutation facilitates tumorigenesis and escape from cellular senescence. Mol. Cell Biol. 22(2), 644-656 (2002).

41 Zhang X, Gaspard JP, Mizukami Y, Li J, Graeme-Cook F, Chung DC. Overexpression of cyclin D1 in pancreatic beta-cells in vivo results in islet hyperplasia without hypoglycemia. Diabetes 54(3), 712-719 (2005).

42 Bai F, Pei XH, Nishikawa T, Smith MD, Xiong Y. p18Ink4c, but not p27Kip1, collaborates with Men1 to suppress neuroendocrine organ tumors. Mol. Cell Biol. 27(4), 1495-1504 (2007).

43 Loffler KA, Biondi CA, Gartside MG et al. Lack of augmentation of tumor spectrum or severity in dual heterozygous Men1 and Rb1 knockout mice. Oncogene 26(27), 4009-4017 (2007).

44 Matoso A, Zhou Z, Hayama R, Flesken-Nikitin A, Nikitin $\mathrm{AY}$. Cell lineage-specific interactions between Men1 and $\mathrm{Rb}$ in neuroendocrine neoplasia. Carcinogenesis 29(3), 620-628 (2008).

45 Gillam MP, Nimbalkar D, Sun L et al. MEN1 tumorigenesis in the pituitary and pancreatic islet requires $\mathrm{Cdk} 4$ but not Cdk2. Oncogene doi:10.1038/onc.2014.3 (2014) (Epub ahead of print).

46 Karnik SK, Hughes CM, Gu X et al. Menin regulates pancreatic islet growth by promoting histone methylation and expression of genes encoding p27Kip1 and p18INK4c. Proc. Natl Acad. Sci. USA 102(41), 14659-14664 (2005).

47 Hughes CM, Rozenblatt-Rosen O, Milne TA et al. Menin associates with a trithorax family histone methyltransferase complex and with the hoxc8 locus. Mol. Cell 13(4), 587-597 (2004).

48 Yokoyama A, Wang Z, Wysocka J et al. Leukemia proto-oncoprotein MLL forms a SET1-like histone 
methyltransferase complex with menin to regulate Hox gene expression. Mol. Cell Biol. 24(13), 5639-5649 (2004).

49 Christensen J, Agger K, Cloos PA et al. RBP2 belongs to a family of demethylases, specific for tri-and dimethylated lysine 4 on histone 3. Cell 128(6), 1063-1076 (2007).

50 Lin W, Cao J, Liu J et al. Loss of the retinoblastoma binding protein 2 (RBP2) histone demethylase suppresses tumorigenesis in mice lacking Rb1 or Men1. Proc. Natl Acad. Sci. USA 108(33), 13379-13386 (2011).

-. The first study in mouse models that links an endocrine tumor of $M E N 1$ with a gene responsible for epigenetic modifications.

51 Walls GV, Reed AA, Jeyabalan J et al. Proliferation rates of multiple endocrine neoplasia type 1 (MEN1)-associated tumors. Endocrinology 153(11), 5167-5179 (2012).

- Demonstrates the use of mouse models of MEN1 endocrine tumors in preclinical studies.

52 Walls GV, Lemos MC, Javid M et al. MEN1 gene replacement therapy reduces proliferation rates in a mouse model of pituitary adenomas. Cancer Res. 72(19), 5060-5068 (2012).
- Demonstrates the use of mouse models of MEN1 endocrine tumors in preclinical studies.

53 Korsisaari N, Ross J, Wu X et al. Blocking vascular endothelial growth factor-A inhibits the growth of pituitary adenomas and lowers serum prolactin level in a mouse model of multiple endocrine neoplasia type 1. Clin. Cancer Res. 14(1), 249-258 (2008).

- Demonstrates the use of mouse models of MEN1 endocrine tumors in preclinical studies.

54 Chu X, Gao X, Jansson L, Quach M, Skogseid B, Barbu A. Multiple microvascular alterations in pancreatic islets and neuroendocrine tumors of a Men1 mouse model. $\mathrm{Am}$. J. Pathol. 182(6), 2355-2367 (2013).

- Demonstrates the use of mouse models of MEN1 endocrine tumors in preclinical studies.

55 Quinn TJ, Yuan Z, Adem A et al. Pasireotide (SOM230) is effective for the treatment of pancreatic neuroendocrine tumors (PNETs) in a multiple endocrine neoplasia type 1 (MEN1) conditional knockout mouse model. Surgery 152(6), 1068-1077 (2012).

- Demonstrates the use of mouse models of MEN1 endocrine tumors in preclinical studies. 